\title{
Ancient supervolcanoes revealed on Mars
}

\section{Giant depressions may be the remains of eruptions rather than old impact craters.}

\section{Alexandra Witze}

02 October 2013

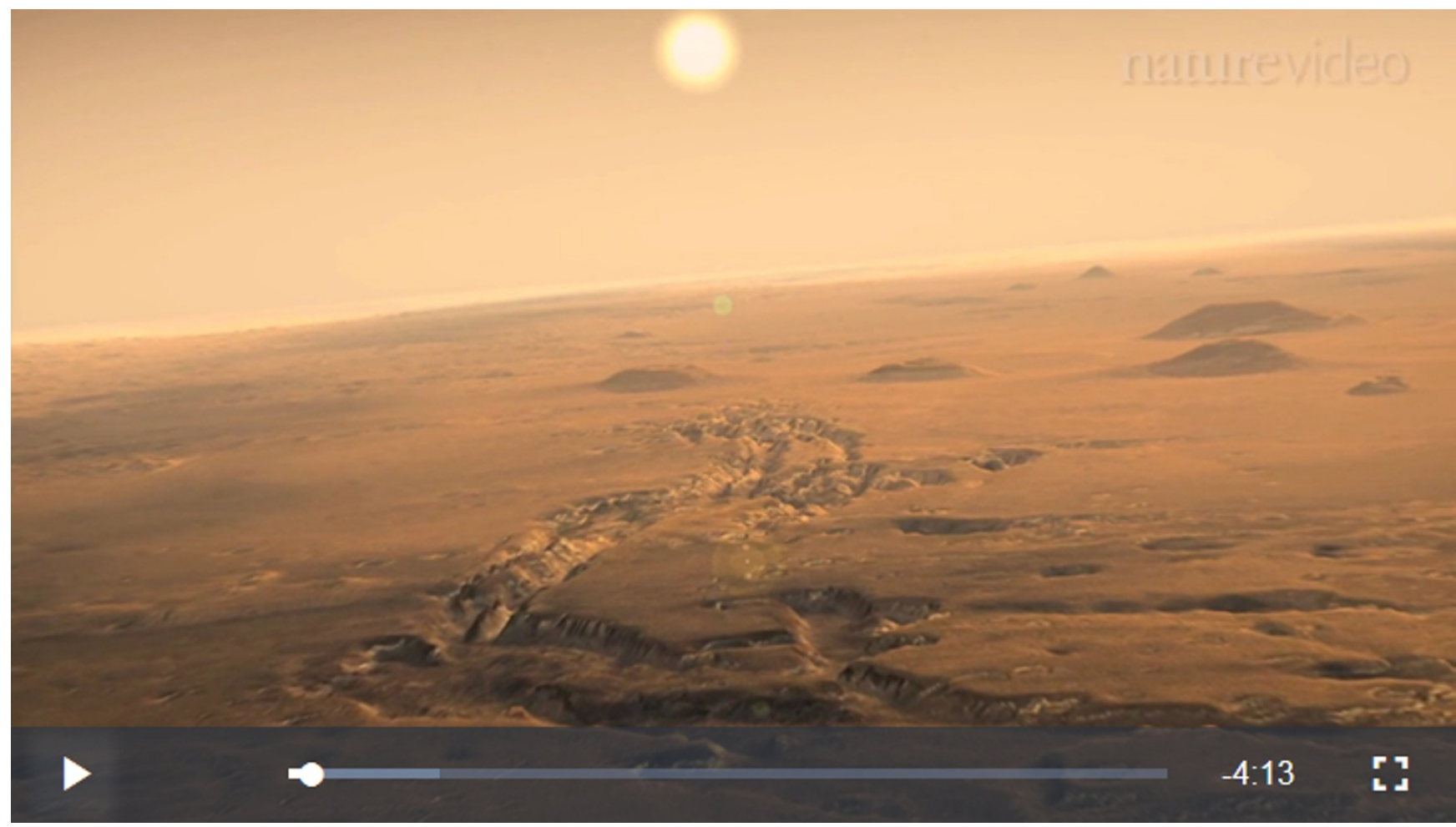

A series of Martian craters assumed to have been formed by meteorites may actually be extinct volcanoes so massive that, when they were active billions of years ago, they could have buried Mars in ash.

The craters pepper the surface of Arabia Terra, a geologically ancient region of northern Mars. They appear as several huge circular pits that resemble Earth's calderas, in which magma beneath a volcano drains after a volcanic eruption, causing the ground above the magma chamber to collapse. The best example on Mars is a feature called Eden patera, a depression about 85 kilometres long, 55 kilometres wide and 1.8 kilometres deep, says Joseph Michalski, a researcher jointly at the Planetary Science Institute in Tucson, Arizona, and at the Natural History Museum in London.

\begin{abstract}
Eden patera, a depression about 85 kilometres long, 55 kilometres wide and 1.8 kilometres deep, is the best example of suspected supervolcanoes on Mars. Its caldera is shown here as a grey bullseye.

NASA/JPL/GSFC/Arizona State University
\end{abstract}

Researchers suspect that Eden patera and other extinct supenolcanoes may have once
- Using data from several satellites orbiting Mars, Michalski and his colleague Jacob Bleacher, a volcanologist at NASA's Goddard Space Flight Center in Greenbelt, Maryland, mapped Eden patera in detail. In a report in Nature today ${ }^{1}$, they describe three separate calderas within the depression, along with possible signs of a lake of solidified lava and a volcanic vent where lava could have oozed out.

"I just don't think it's an impact crater," Michalski says. Another possible explanation is that underground ice could have melted and formed the depression, but ice typically isn't known to form such big features.

\section{Rubble raisers}

Rather, Michalski and Bleacher argue that an entirely new category of volcanoes once existed - on Mars: ones that rivalled supervolcanoes on Earth, such as that underlying Yellowstone National Park in the western United States. Supervolcanoes are loosely defined as those that erupt at least 1,000 cubic kilometres of rock, ash and other debris in a single blast. Given their dimensions, Martian supervolcanoes such as Eden could have spewed out enough ash to cover much of Mars in their rubble, Michalski says. 
No one had recognized these features as supervolcanoes until now because researchers thought that the giant depressions were just eroded impact craters, Michalski says.

The idea is likely to stir controversy. "I wouldn't say l'm convinced, but it's certainly a plausible idea worth getting out there," says Brian Hynek, a planetary geologist at the University of Colorado Boulder, who has studied how volcanic material is spread around Mars.

These ancient volcanoes would have been fundamentally different from others on Mars. The planet's famous Olympus Mons, one of the biggest volcanoes in the Solar System at 625 kilometres across, would have quietly oozed lava for billions of years. By contrast, the ancient Arabian volcanoes would have blasted out ash ferociously, perhaps because their magma was wetter or rose through the planet's crust more quickly, Michalski suggests.

Either way, the Arabian volcanoes were probably active only in the first billion years of Martian history, and then ceased to erupt. They are likely to have played a big part in the early evolution of Mars, says Hynek - maybe even helping to create environments that were conducive to life.

Nature | doi:10.1038/nature.2013.13857

\section{References}

1. Michalski, J. R. \& Bleacher, J. E. Nature 502, 47-52 (2013). 